\title{
Peningkatan Proses Pembelajaran Tematik Terpadu dengan Menggunakan Model Problem Based Learning (PBL) Berbasis TPACK di Kelas V SDN 07 Pandam Gadang
}

\author{
Stefani ${ }^{1}$, Nikmat Elva $^{2}$, Cici Sumiati ${ }^{3}$ \\ ${ }^{1}$ Program Pendidikan Profesi Guru, Universitas Negeri Padang \\ 2 Program Pendidikan Profesi Guru, Universitas Negeri Padang \\ ${ }^{3}$ Sekolah Dasar Negeri 20 Indarung, Padang, Indonesia \\ e-mail: stefanyyy17@gmail.com
}

\begin{abstract}
Abstrak
Penelitian ini bertujuan untuk mendeskripsikan penggunaan model Problem Based Learning (PBL) Berbasis Thecnological, Pedagogical And Content Knowledge (TPACK) untuk meningkatkan proses pembelajaran tematik terpadu di kelas V SDN 07 Pandam Gadang. Penelitian ini merupakan penelitian tindakan kelas (Classroom Action Research), yang menggunakan pendekatan kualitatif dan kuantitatif. Penelitian ini dilaksanakan dua siklus dengan tiga kali pertemuan yang meliputi empat tahapan yaitu perencanaan, pelaksanaan, pengamatan, dan kemudian refleksi. Subjek penelitian ini yaitu peneliti, guru, dan siswa kelas V SDN 07 Pandam Gadang. Hasil penelitian yaitu (1) persentase pengamatan Rencana Pelaksanaan Pebeljaaran (RPP) 81,93\% meningkat 94,44\%. (2) Persentase aktivitas guru $82,14 \%$ meningkat $96,42 \%$. (3) Persentase aktivitas siswa $82,14 \%$ meningkat 96,42\%. Hasil penelitian menunjukkan bahwa model Problem Based Learning (PBL) Berbasis Thecnological, Pedagogical And Content Knowledge (TPACK) dapat meningkatkan proses pembelajaran tematik terpadu di kelas sekolah dasar.
\end{abstract}

Kata kunci: Problem Based Learning, TPACK, Pembelajaran Tematik Terpadu

\begin{abstract}
This study aims to describe the use of the Based Problem Based Learning (PBL) Thecnological, Pedagogical And Content Knowledge model (TPACK) to improve the integrated thematic learning process in class V SDN 07 Pandam Gadang. This research is a classroom action research (CAR), which uses a qualitative and quantitative approach. This research was carried out in two cycles with three meetings covering four stages, namely planning, implementation, observation, and then reflection. The subjects of this study were researchers, teachers, and fifth grade students at SDN 07 Pandam Gadang. The results of the study were (1) the percentage of lesson plan observation was $81.93 \%$, an increase of $94.44 \%$. (2) The percentage of teacher activity is $82.14 \%$, an increase of $96.42 \%$. (3) The percentage of student activity is $82.14 \%$, an increase of $96.42 \%$. The results showed that the Problem Based Learning (PBL) based on model Thecnological, Pedagogical And Content Knowledge (TPACK) can improve the integrated thematic learning process in elementary school classes.
\end{abstract}

Keywords : Problem Based Learning, TPACK, Integrated thematic learning

\section{PENDAHULUAN}

Sejalan dengan berkembangnya ilmu pengetahuan dan teknologi, pemerintah Indonesia mengusahakan peningkatan mutu dan pengelolaan pendidikan dengan melakukan penyempurnaan kurikulum menjadi kurikulum 2013. Pendekatan pembelajaran yang digunakan pada kurikulum 2013 ialah pembelajaran tematik terpadu. Pembelajaran tematik terpadu adalah pendekatan pembelajaran yang menggunakan tema sebagai fokus 
utama dengan tujuan memberikan pengalaman yang bermakna bagi para siswa (Faisal, 2014).

Pembelajaran terpadu ini dilaksanakan sesuai dengan pengalaman belajar siswa yang kemudian dikemas dalam satu tema atau topik tertentu, setiap mata pelajaran atau bidang studi lain harus mengaitkan materi yang sudah dibahas dari berbagai sudut pandang atau disiplin keilmuan dalam satu kemasan tema atau topik yang sudah direncanakan sebelumnya. Pengemasan materi dalam tema diusahakan agar siswa dapat mudah memahaminya. Oleh sebab itu, dalam penyusunannya harus dibuat dengan semenarik mungkin, agar siswa tertarik untuk belajar dan dengan mudah dapat menyerap pengetahuan yang mereka peroleh dari materi tersebut (Tirtoni, 2018). Sejalan dengan yang disampaikan oleh Tirtoni perkembangan teknologi saat ini tentunya dapat dimanfaatkan oleh guru untuk melaksanakan pembelajaran tematik terpadu yang menarik bagi siswa.

Proses pembelajaran tematik terpadu meliputi interaksi semua komponen yang terdapat dalam pembelajaran yang satu sama lainnya saling berhubungan dalam mencapai tujuan pembelajaran. Hal yang termasuk komponen pembelajaran antara lain tujuan intruksional yang hendak dicapai, materi pelajaran, metode mengajar, alat peraga pengajaran, dan evaluasi sebagai alat ukur tercapai atau tidaknya tujuan pembelajaran (Suprihatiningrum, 2014).

Pembelajaran tematik terpadu menuntut keterampilan setiap guru untuk mampu merencanakan dan melaksanakan pembelajaran yang menarik dan baik bagi para siswa. Dilihat dari aspek rencana pelaksanaan pembelajaran, guru haruslah terampil dalam mengembangkan komponen-komponen RPP yang ada pada buku guru, kemudian disesuaikan dengan situasi, kondisi, dan karakteristik siswa. Rencana pelaksanaan pembelajaran juga harus menerapkan model pembelajaran yang tepat, berpusat pada siswa, dan berbasis TPACK. Sehingga dapat membuat siswa aktif, kreatif dan bersemangat selama proses belajar serta tujuan pembelajaran dapat tercapai dengan sebagaimana mestinya.

Kemudian dilihat dari pelaksanaannya pembelajaran tematik terpadu menuntut keterampilan guru dalam mengaitkan materi antar mata pelajaran, melaksanakan pembelajaran dengan menerapkan model pembelajaran yang tepat, mengintegrasikan teknologi dalam membangun pengetahuan siswa, kemudian guru harus mampu menciptakan suasana belajar yang membuat siswa aktif, kreatif, mampu berpikir kritis, serta mampu bekerja sama dalam memecahkan masalah nyata yang dekat dengan lingkungan siswa sendiri. Sehingga seluruh kegiatan pembelajaran akan lebih berpusat pada siswa. Untuk itu peranan teknologi sangatlah dibutuhkan dalam pendidikan, karena pada dasarnya teknologi dan pengetahuan adalah satu kesatuan yang tidak dapat dipisahkan.

Namun pada nyatanya masih banyak guru yang belum mengintegrasikan teknologi, pedagogik, dan pengetahuan dalam proses pembelajaran. Padahal ketiga komponen tersebut idealnya dapat membantu tercapainya tujuan dari pelaksanaan pembeljaaran. Hal ini terjadi disebabkan oleh beberapa faktor, salah satunya yaitu keterbatasan jaringan di daerah pedalaman, sehingga guru kesulitan dalam mengakses teknologi. Sehingga disaat jaringan telah merata, banyak guru yang tidak melek teknologi untuk mengaplikasikannya dalam pembelajaran.

Berdasarkan hasil observasi yang peneliti lakukan di kelas V SD Negeri 07 Pandam peneliti temukan bahwa Rencana Pelaksanaan Pembelajaran (RPP) yang digunakan guru belum dikembangkan sesuai situasi, kondisi,dan karakteristik siswa. Seharusnya RPP tersebut dikembangkan dengan menggunakan model pembelajaran yang tepat, berbasis teknologi, dan disesuaikan dengan kondisi, serta karakteristik siswa.

Kemudian pada pelaksanaan pembelajaran, peneliti temukan beberapa masalah atau persoalan yang dialami oleh guru, antara lain ; (1) Model pembelajaran yang digunakan oleh guru belum tepat sesuai dengan situasi, kondisi, dan karakteristik siswa, (2) Pembelajaran masih berpusat kepada guru, (3) Pembelajaran dilaksanakan dengan waktu singkat dikarenakan adanya pandemic Covid-19 sehingga pembelajaran kurang dikaitkan 
dengan masalah-masalah nyata yang dekat dengan lingkungan siswa, (4) Pengunaan teknologi sebagai penunjang pelaksanaan pembelajaran masih sangat minim.

Permasalahan yang dialami guru tersebut berdampak kepada siswa, seperti : siswa kurang dapat mengembangkan kemampuan berpikir kritis dalam memecahkan masalah nyata yang dekat dengan lingkungan siswa, siswa kurang aktif bekerjasama di dalam kelompok, dan siswa tidak bersemangat selama proses pembelajaran berlangsung.

Permasalahan di atas dapat diatasi apabila guru mampu memilih model pembelajaran yang tepat. Salah satu model pembelajaran yang dapat digunakan untuk mengatasi permasalahan di atas adalah Model Problem Based Learning (PBL). Model PBL merupakan suatu model pembelajaran yang menggunakan masalah nyata yang dekat dengan siswa sebagai fokus utama, kemudian mengkondisikan siswa berpikir kritis untuk mencari solusi terhadap permasalahan yang telah diajukan sehingga siswa dengan sendirinya dapat memperoleh pengetahuan dan keterampilan yang esensial dari apa yang telah dipelajari (Faisal, 2014). Kemudian dijelaskan juga bahwa model Pembelajaran PBL adalah sebuah model pembelajaran yang menghadapkan siswa terhadap masalah nyata dalam kehidupan sehari-hari yang mesti dicari solusinya, dengan tujuan agar membuat siswa aktif belajar dan dapat menciptakan pengalaman belajar bagi siswa itu sendiri (Setiyaningrum, 2018). keunggulan dari model Problem Based Learning (PBL) adalah siswa terlatih berfikir kritis dan memiliki keterampilan untuk memecahkan masalah yang akan ditemuinya dalam kehidupan sehari- hari sehingga pembelajaran menjadi bermakna. Hosnan (2014) mengemukakan sintak model PBL dalam pelaksanaan pembelajaran sebagi berikut :

Diagram 1. Sintak Model Problem Based Learning (PBL)

\begin{tabular}{|l|l|}
\hline \multicolumn{1}{|c|}{ Tahap } & \multicolumn{1}{|c|}{ Aktivitas Guru dan Peserta didik } \\
\hline $\begin{array}{l}\text { Tahap 1 } \\
\text { tengorientasikan peserta didik masalah }\end{array}$ & $\begin{array}{l}\text { Guru menjelaskan tujuan pembelajaran dan sarana } \\
\text { atau logistik yang dibutuhkan. Guru memotivasi } \\
\text { peserta didik untuk terlibat dalam aktivitas } \\
\text { pemecahan masalah nyata yang dipilih atau } \\
\text { ditentukan. }\end{array}$ \\
\hline $\begin{array}{l}\text { Tahap 2 } \\
\text { Mengorganisasi peserta didik untuk } \\
\text { belajar }\end{array}$ & $\begin{array}{l}\text { Guru membantu peserta didik untuk mendefenisikan } \\
\text { dan mengorganisasi tugas belajar yang berhubungan } \\
\text { dengan masalah yang sudah diorientasikan pada } \\
\text { tahap sebelumnya. }\end{array}$ \\
\hline $\begin{array}{l}\text { Tahap 3 } \\
\text { Membimbing penyelidikan individual } \\
\text { maupun kelompok }\end{array}$ & $\begin{array}{l}\text { Guru mendorong peserta didik untuk mengumpulkan } \\
\text { informasi yang sesuai dan melaksanakan } \\
\text { eksperimen untuk mendapatkan kejelasan yang } \\
\text { diperlukan untuk menyelesaikan masalah }\end{array}$ \\
\hline $\begin{array}{l}\text { Tahap 4 } \\
\text { Mengembangkan dan menyajikan } \\
\text { hasil karya }\end{array}$ & $\begin{array}{l}\text { Guru membatu peserta didik untuk berbagi tugas dan } \\
\text { merencanakan atau menyiapkan karya yang sesuai } \\
\text { sebagai hasil pemecahan masalah dalam bentuk } \\
\text { laporan, video, atau model. }\end{array}$ \\
\hline $\begin{array}{l}\text { Tahap 5 menganalisi dan mengevaluasi } \\
\text { Mroses pemecahan masalah }\end{array}$ & $\begin{array}{l}\text { Guru membantu peserta didik untuk melakukan } \\
\text { refleksi atau evaluasi terhadap proses pemecahan } \\
\text { masalah yang dilakukan. }\end{array}$ \\
\hline
\end{tabular}

Selain itu untuk mencapai tujuan pembelajaran dan meminimalisir setiap hambatanhambatan tercapainya tujuan pembelajaran, diperlukan adanya pembaharuan dalam proses pembelajaran salah satunya yaitu dengan pengintegrasian technological, pedagogical, and content knowledge pada proses pembelajaran atau disebut juga pembelajaran berbasis TPACK. Knowledge and technology are interrelated and influence each other in life artinya Pengetahuan dan teknologi merupakan hal yang saling berkaitan serta memberi pengaruh satu sama lain di dalam kehidupan. Teknologi sudah menjadi sesuatu yang akrab dalam kehidupan siswa. Oleh karena itu, guru tidak hanya mengintegrasikan teknologi, tetapi guru memadukannya dengan pendagogi dan pengetahuan (Syahrul, 2021). Teknologi 
merupakan hasil dari perkembangan ilmu pengetahuan, yang terjadi di dunia pendidikan. Oleh karena itu, sudah selayaknya pendidikan sendiri juga memanfaatkan teknologi untuk membantu pelaksanaan pembelajaran (Lestari, 2018).

Mishra \& Koehler menjelaskan bahwa prinsip dari TPACK merupakan penggabungan antara teknologi, pedagogi, isi atau materi yang diterapkan dalam satu konteks (Joko Suyamto, 2020).

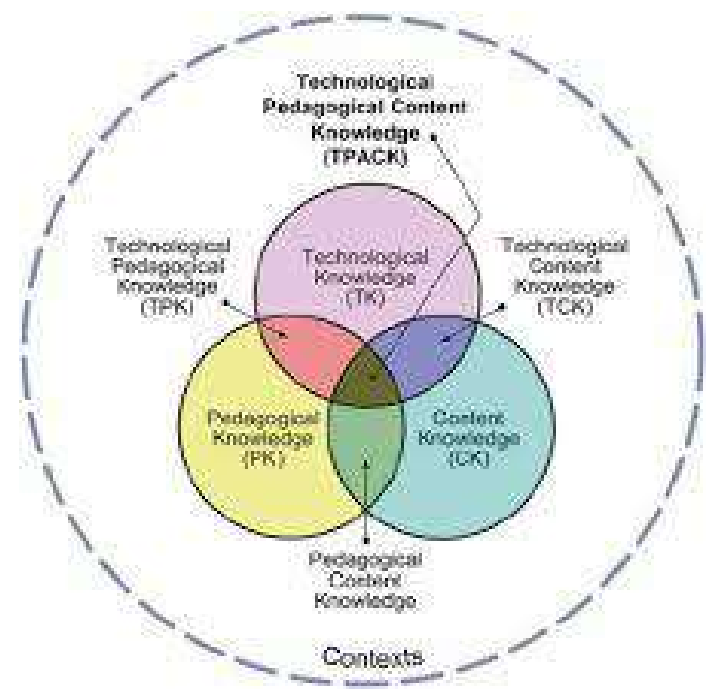

\section{Gambar 1. Framework TPACK dari Mishra \&Koehler}

Dengan TPACK, membuat pembelajaran lebih efektif dan efisien. Seorang guru yang professional haruslah memiliki kompetensi TPACK, dikarenakan TPACK masuk dalm empat kompetensi yang harus dimiliki oleh seorang guru yaitu pedagogic, kepribadian, social, dan profesional. Oleh sebab itu pola pengembangan kompetensi guru dengan TPACK merupakan jalan yang sesuai untuk menjamin terlaksananya pembelajaran yang sesuai dengan tuntutan dan perubahan yang terjadi (Joko Suyamto, 2020).

Berdasarkan paparan di atas, maka secara umum artikel ini bertujuan untuk mendeskripsikan peningkatan proses pembelajaran tematik terpadu dengan menggunakan model Problem Based Learning (PBL) Berbasis TPACK di kelas V Sekolah Dasar.

\section{METODE PENELITIAN}

Penelitian ini menggunakan jenis penelitian tindakan kelas (PTK). Menurut Salim dkk $(2015: 19)$ "Penelitian tindakan kelas adalah penelitian yang dilaksanakan di dalam kelas ketika pembelajaran berlangsung, dengan tujuan untuk memperbaiki atau meningkatkan kualitas pembelajaran". Penelitian tindakan kelas ini dilakukan dengan menggunakan pendekatan kualitatif dan kuantitatif, penelitian ini dilaksanakan di kelas V SDN 07 Pandam Gadang. Waktu penelitian ini dilaksanakan pada semester II tahun ajaran 2020/2021. Subjek penelitian ini guru dan siswa kelas V SDN 07 Pandam Gadang.

Data penelitian ini berupa hasil pengamatan dari setiap tindakan dalam pembelajaran tematik terpadu menggunakan model Problem Based Learning Berbasis TPACK di kelas V SDN 07 Pandam Gadang. Data tersebut berkaitan dengan perencanaan, pelaksanaan yang berupa informasi sebagai berikut: a. Rencana Pelaksanaan Pembelajaran (RPP) yang berhubungan dengan persiapan guru sebelum mengajar, $b$. Pelaksanaan pembelajaran tematik terpadu yang berhubungan dengan aspek guru dan aspek siswa dari kegiatan awal, inti, dan penutup yang berfokus pada proses pembelajaran tematik terpadu. Sumber data penelitian ini adalah proses pembelajaran tematik terpadu dengan model Problem Based Learning Berbasis TPACK di kelas V Sekolah Dasar, yakni meliputi perencanaan, pelaksanaan, pengamatan, dan refleksi pembelajaran tematik terpadu dengan model Problem Based Learning Berbasis TPACK di kelas V Sekolah Dasar. 
Data penelitian dikumpulkan menggunakan teknik pengumpulan data berupa observasi. Data penelitian dianalisis dengan menggunakan analisis data kualitatif dan kuantitatif. Data kualitatif adalah data berupa kata-kata. Sedangkan analisis data kuantitatif menurut Kemendikbud (2014) dapat diperoleh dengan mengggunakan rumus:

Nilai $=\frac{\text { Jumlah skor yang diperoleh }}{\text { Jumlah skor maksimal }} \times 100$

\section{HASIL DAN PEMBAHASAN}

Penelitian ini dilaksanakan sebanyak dua siklus. Perencanaan yang dilakukan pada siklus I dan siklus II yaitu menganalisis kompetensi dasar yang dikembangkan berdasarkan kurikulum 2013 serta merancang rencana pelaksanaan pembelajaran dengan menggunakan model Problem Based Learning Berbasis TPACK. Kemudian diikuti dengan pelaksanaan proses pembelajaran berdasarkan rencana pelaksanaan pembelajaran yang telah dibuat.

Penelitian pada siklus dilaksanakan pada hari Selasa 13 April 2021 pukul 08.3011.30 WIB dan Jum'at 16 April 2021 pukul 08.30-11.30 WIB. Sedangkan siklus II dilaksanakan pada hari Rabu, 21 April 2021 pukul 08.30-11.30 WIB. Dalam pelaksanaan penelitian ini peneliti bertindak sebagai guru dan guru kelas $V$ sebagai observer. Hasil penelitian menunjukkan terdapat peningkatan proses pembelajaran dari siklus I ke Siklus II pada setiap pertemuannya.

Berdasarkan hasil pengamatan rencana pelaksanaan pembelajaran dengan model Problem Based Learning Berbasis TPACK siklus I memperoleh persentase dengan rata-rata $81,93 \%$ kualifikasi baik (B), hasil pengamatan aktivitas guru dengan menggunakan model Problem Based Learning Berbasis TPACK siklus I memperoleh persentase dengan ratarata $82,14 \%$ dengan kualifikasi baik (B), dan hasil pengamatan aktivitas siswa dengan menggunakan model Problem Based Learning Berbasis TPACK siklus I memperoleh persentase dengan rata-rata $82,14 \%$ dengan kualifikasi baik (B).

Selanjutnya berdasarkan hasil pengamatan rencana pelaksanaan pembelajaran dengan model Problem Based Learning Berbasis TPACK siklus II nilai yang didapat pada siklus II adalah 94,44\% dengan kualifikasi sangat baik (SB), untuk hasil pengamatan aktivitas guru dengan menggunakan model Problem Based Learning Berbasis TPACK diperoleh persentase skor pelaksanaan aspek guru siklus II adalah 96,42\% dengan kualifikasi sangat baik (SB), dan kemudian untuk hasil pengamatan aktivitas siswa dengan menggunakan model Problem Based Learning Berbasis TPACK diperoleh persentase skor pelaksanaan aspek siswa siklus II adalah $96,42 \%$ dengan kualifikasi sangat baik (SB).

Berdasarkan peningkatan yang signifikan pada hasil pengamatan di siklus I dan siklus II maka penelitian tidak dilanjutkan dan dihentikan pada siklus II. Dalam artian penggunaan model Problem Based Learning (PBL) Berbasis TPACK dapat meningkatkan proses pembelajaran tematik terpadu di sekolah dasar. Untuk lebih jelasnya, peningkatan proses pembelajaran tematik terpadu dengan menggunakan model Problem Based Learning (PBL) Berbasis TPACK Di Kelas V SDN 07 Pandam Gadang dapat dilihat pada diagram berikut:

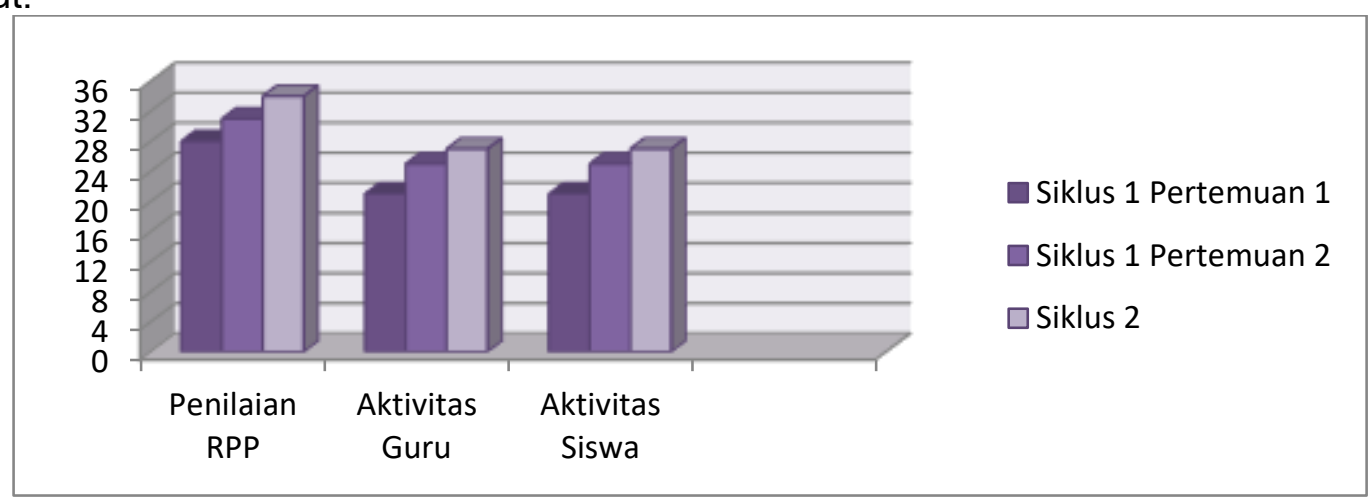

Diagram 1. Rekapitulasi Hasil Pengamatan Siklus I dan Siklus II 


\section{SIMPULAN}

Berdasarkan hasil penelitian dapat disimpulkan bahwa penelitian ini telah menunjukkan peningkatan proses pembelajaran tematik terpadu yang meliputi RPP dan pelaksanaan pembelajaran. Persentase skor yang diperoleh pada aspek RPP Siklus I yaitu $81,93 \%$ dengan kualifikasi baik, sedangkan pada siklus II 94,44\% dengan kualifikasi sangat baik. Persentase skor yang diperoleh untuk aspek guru dan aspek siswa pada siklus I yaitu $82,14 \%$ dengan kualifikasi baik, dan memperoleh persentase skor $96,42 \%$ pada siklus II dengan kualifikasi sangat baik. Hal ini membuktikan bahwa terdapat peningkatan proses pembelajaran tematik terpadu dengan menggunakan model Problem Based Learning Berbasis TPACK di kelas V SDN 07 Pandam Gadang.

\section{DAFTAR PUSTAKA}

Faisal. (2014). Sukses Mengawal Kurikulum 2013 di SD (Teori dan Aplikasi). Yogyakarta: Diandra Creative.

Hosnan. 2014. Pendekatan Saintifik dan Kontekstual dalam Pembelajaran Abad 21. Jakarta : Ghalia Indonesia

Joko Suyamto, dkk. (2020). ANALISIS KEMAMPUAN TPACK (TECHNOLGICAL, PEDAGOGICAL, AND CONTENT, KNOWLEDGE) GURU BIOLOGI SMA DALAM MENYUSUN PERANGKAT PEMBELAJARAN MATERI SISTEM PEREDARAN DARAH. INKUIRI : Jurnal Pendidikan IPA.

Lestari, S. (2018). Peran Teknologi Dalam Pendidikan di Era Globalisasi. Edureligia.

Salim,dkk. 2016. Penelitian Tindakan Kelas. Medan: Perdana Publishing

Setiyaningrum, M. (2018). Peningkatan Hasil Belajar Menggunakan Model Problem Based Learning (PBL) Pada Siswa Kelas 5 Sd. Jurnal Riset Teknologi Dan Inovasi Pendidikan.

Suprihatiningrum, J. (2014). Strategi Pembelajaran. Yogyakarta: Ar-Ruzz Media.

Syahrul, dkk. (2021). Multimedia With Social LearningNetworks (SNL): As Learning Innovation in the 4.0 Industrial Era. Journal Of Physics: Conference Series doi.

Tirtoni, F. (2018). Pembelaaran Terpadu di Sekolah Dasar. Sidoarjo: Umsida Press. 